\title{
Very Poor Survival after Reirradiation
}

National Cancer Institute

\section{Source}

National Cancer Institute. Very Poor Survival after Reirradiation. NCI Thesaurus. Code C127870.

A score of 4 on the Combs Prognostic Index scale. 